\title{
Trouble-making, Transformation, and Tradition: A Transcultural Review of Nurse Leaders' Perspectives in the Republic of Ireland
}

\begin{abstract}
By Victoria Hughes ${ }^{*}$, Kimberly Priode $e^{ \pm} \&$ Jennifer Wenzel ${ }^{*}$
The purpose of this study was to understand nurse leadership development within the Irish context. Limited literature is published related to nursing leadership development within small island countries. Explorative semi structured interviews, underpinned by a phenomenology philosophy, were conducted to understand the ascribed meaning of nurse leadership development experiences within the Irish context. The major themes from this study included: leadership strategies, political acumen, cultural influence, and gender norms. The Republic of Ireland nurse leaders used participatory leadership styles, assertive communication, and political acumen to influence the advancement of national policies, nursing education and advanced practice opportunities.
\end{abstract}

Keywords: Nursing leadership development, nurse leaders, professional success, Ireland

\section{Introduction}

Development of nurse leaders is increasingly important with the growing complexity of health care practice environments. Researchers have long recognized that in studying social phenomenon, such as leadership, one must consider the setting in which leadership is practiced (Alvesson and Sveningsson 2003). Examining the past can help us understand the present and even the future. Little information has been published on the leadership development of nurses within small island countries. This study will examine the lived experiences of nurse leaders from the Republic of Ireland. Ireland, which is located between the United Kingdom and the Atlantic Ocean, is divided into Northern Ireland and the Republic of Ireland. The two areas of Ireland have been separated for nearly 100 years, beginning with the Irish War of Independence (1991-1921) from the British state. Northern Ireland is predominately Protestant Christian, but the Republic of Ireland is mainly Catholic Christian religion (Scroope 2007).

According to a report submitted to the Minister for Health and Children in 1998, three major influences shaped nursing as a profession in Ireland: the religious orders of nursing sisters, scientific progression in prevention and treatment of disease, and the life and writings of Florence Nightingale (Commission on Nursing 1998). Proper training of nurses was initiated following the 1879 Report

\footnotetext{
*Assistant Professor, School of Nursing, Johns Hopkins University, USA.

${ }^{ \pm}$Dean, May School of Nursing and Health Sciences, Lees-McRae College, USA.

${ }^{\ddagger}$ Associate Professor, School of Nursing, Johns Hopkins University, USA.
} 
on Nursing Arrangements in the Dublin Hospitals Receiving Aid from the Dublin Hospital Sunday Fund. The Dublin Hospitals Commission of 1887 implemented the recommendations from the 1879 Report in all voluntary hospitals in Dublin (Fealy 2005). The first cadre of lady hospital superintendents was elite women, who by virtue of their social circumstances and achievements in reforming nursing, became the first leaders of modern nursing in Ireland. Most of these leaders were educated gentlewomen, who received training in the reformed Anglican voluntary hospitals in England, and were daughters of doctors, military officers or gentlemen (Fealy 2005). The first general nursing training schools in Ireland were officially established in 1923 (Leydon 1973).

In 1950 the Nurses Act established the Nursing Board to replace both the General Nursing Counsel of Ireland and the Central Midwives Board and to govern the education and registration of basic nursing programs (Leydon 1973). In 1997, the Commission on Nursing by the Minister of health was established and recognized nursing's contribution to Irish health (O'Dwyer 2007). The Commission on Nursing (1998) recommended the establishment of a National Council for the Professional Development of Nursing and Midwifery, as an independent statutory body, to give guidance and direction in relation to the development of specialist nursing and midwifery post-registration educational programs offered to nurses and midwives in response to the context of anticipated changes in health services (Commission on Nursing 1998). The commission justified the need for the National Council to respond to a constant state of technological, social and economic changes in Ireland and internationally (Commission on Nursing 1998). In 2002, the first Irish pre-licensure nursing degree programs were introduced in universities and colleges. The first cohort of nurse graduates entered the Irish hospital workforce in 2006 (O'Dwyer 2007). During the past 10-20 years of fluctuating financial, political and social changes in Ireland, the nursing profession has adapted, transitioned, and evolved to meet the healthcare needs. In the context of the constantly changing healthcare system in Ireland, nurse leaders were invited to share their views and the experiences that contributed to their growth as leaders.

\section{Methods}

Explorative semi structured interviews, underpinned by a phenomenology philosophy (Teherani et al. 2015), were conducted to understand the ascribed meaning of nurse leadership development experiences within the Irish context. Van Manen (1990) posits that we learn from being immersed within the lived experiences shared by others creating opportunities to understand and learn from them. These lived experiences include the inquiry and focus of a process that contributes to nursing practice through the lens of culture (van Manen 1990). 


\section{Procedure}

As part of a larger Johns Hopkins University IRB approved study exploring European leadership development in four island countries, four Irish nurses employed as leaders in academic, administrative, and advanced clinical roles were interviewed regarding their leadership development. The primary investigator used semi structured, guided interviews with participants to explore and understand their views on leadership development within the Irish culture.

Sample

Purposeful sampling was used to identify four nurse leaders. A nurse leader in Ireland provided an email introduction from primary investigator to nurses serving in clinical, administrative and academic leadership roles. The nurse leaders expressed email consent to be interviewed and later verbal and written consent to participate in the study. All of the interviews took place in Dublin, Ireland at locations chosen by the participants. Three nurse leaders were interviewed in person and one nurse leader was interviewed via telephone.

\section{Data Analysis}

This was accomplished by the following: (1) collecting data with the raw data from notes on interview survey, (2) coding and classification, (3) identifying recurrent themes in this study by two expert researchers with the creation of coding trees to illuminate how interpretative themes of leadership were developed within the nursing culture of the Irish, and (4) identifying major themes and recommendations lifted from the context of the coding trees.

The development and utilization of the coding tree from the raw data presented on written transcripts provided a high level of structure. All three authors are experienced qualitative researchers. Each researcher constructed their individual coding tree signifying personal interpretation. The coding process included the task of identifying common words and phrases with the first coding selection signified as the first coding column on the coding tree. The first coding process reflected responses from the participants reaching saturation. Denzin and Lincoln (2018) described the credibility of illuminating the common theme of qualitative inquiry by formulating the saturation of the findings (Denzin and Lincoln 2018). In this study, saturation was accomplished for each theme as each participant was found to have similar responses.

The second axial coding process included these common words and phrases to be linked which allowed themes to emerge and represented by the second coding column on the coding tree. The final coding process, reflected by the third column on the coding tree, included these common themes to be broadly interpreted and sanctioned. As a final review, signifying constant individual and collaborative comparison (Cruz and Higginbottom 2013), each researcher reviewed individual coding trees for further interpretation and confirmation, then 
the individual coding trees were shared. Final themes were realized after collaboration between the researchers. Only one disagreement occurred between researchers on the completion of themes for this research. With further review of raw data and discussion about the themes, final agreement was reached. Consensus was based upon a renaming of the theme.

Important for determining validity for any qualitative inquiry is the establishment of rigor or trustworthiness (Creswell and Poth 2018). The rigor for this study was enhanced by constant comparison between two expert researchers familiar with the process. Creswell and Poth (2018) emphasize the importance of an audit trail to establish rigor (Creswell and Poth 2018). The audit trail for this study was established by including written survey notes, the development of a coding tree, both individually and collaboratively, and confirmation of selected themes in the software, Nvivo. Morse (2015) argued that the use of prolonged engagement should be used to establish rigor in qualitative studies (Morse 2015). The expertise of the research interviewers for this study includes the many years of service in leadership positions within both military and civilian settings. Both research interviewers have experienced backgrounds with managerial positions and leadership roles affording their ability to understand, represent, and evaluate leadership development. Prolonged engagement also occurred by the researcher in this study personally interviewing the Irish nurses using an interview guide with the same credible research questions.

\section{Findings}

Table 1. Irish Nurse Leader Themes and Subthemes

\begin{tabular}{|c|c|}
\hline $\begin{array}{r}\text { Broad Theme: } \\
\text { Leadership } \\
\text { Strategies }\end{array}$ & $\begin{array}{l}\text {-Subthemes } \\
\text {-Inspiration } \\
\text {-Influence } \\
\text {-Individuals Consideration } \\
\text {-Intellectual Growth } \\
\text {-Transformatng Nursing }\end{array}$ \\
\hline $\begin{array}{l}\text { Broad Theme: } \\
\text { Political Acumen }\end{array}$ & $\begin{array}{l}\text {-Subthemes } \\
\text { - Connection } \\
\text { - Reputation/Integrity } \\
\text { - Strategies to Influence }\end{array}$ \\
\hline $\begin{array}{r}\text { Broad Theme: } \\
\text { Cultural } \\
\text { Influence }\end{array}$ & $\begin{array}{l}\text {-Subtheme } \\
\text { - Traditional } \\
\text {-International influence } \\
\text { - Humor }\end{array}$ \\
\hline $\begin{array}{l}\text { Broad Theme: } \\
\text { Gender Norms }\end{array}$ & $\begin{array}{l}\text {-Subthemes } \\
\text { - Communication Style } \\
\text { - Traditional Female Role } \\
\text { - Changing Strategies to Succeed in Leadership Role }\end{array}$ \\
\hline
\end{tabular}


The major themes expressed through the lens of highlighting lived experiences from this study include: leadership strategies, political acumen, cultural influence, and gender norms (Table 1).

\section{Leadership Strategies}

The Irish nurses in this study described how they created change within their roles while developing leadership qualities. Participants identified strategies such as role model, establishing a vision, genuine concern for followers, continued professional development, and innovation. For quote citations, $\mathrm{P}$ will stand for participant and Q will stand for corresponding question. Examples of being a role model are listed below:

"Start off as you need to be. Be the person that you want to be. Do not try to tip toe around people. You have to draw a line. You are no longer the friend but the leader" (P3, Q10).

"Establish what you want. When you know what you want then can negotiate better. It is not about you. Do not take it personally. Stay patient focused and don't down play your influence as a nurse" (P1, Q10).

"Be brave; be bold; trust instincts; be true to self; and connect and collaborate. Don't be afraid to take calculated risk" (P2, Q10).

"Solve problems as they come. Bounce back from the problem and ask for solutions so that people can think on their own" (P3, Q10).

The Irish nurse leaders discussed the importance of inspiring others. Establishing a clear vision was seen as an important strategy for inspiring others as evidenced by the statements below:

"A leader has a vision. (I) evolved as a leader. I saw the need to make changes. I pursued further education to lead the change needed in academic level" (P4, Q1). " (You) need to be a vision maker" (P4, Q4).

"The buck stops with me. I am the voice for nursing (to help create the) strategic vision for next 3 years. (This is) unique for the nursing board" (P3, Q7).

"Because I wanted to make a difference and I was capable. I could influence" (P2, Q1).

Many of the Irish nurse leaders described a genuine concern for the development of their followers.

"Good leaders need to work hard and not be afraid to let others share the credit...a good leader does not produce a climate of fear but of respect" (P4, Final Comments).

"Solve problems as they come. Bounce back the problem and ask for solutions so that people think on their own" (P3, Q10).

Several of the participants focused on a leadership need to continue to grow, develop, and innovate.

"I pursued further education to lead the change needed" (P4, Q1). 
"Felt stifled in job and needed to take on more responsibility. When I first took on the role I did not feel qualified. I went back to do post graduate degree and often worked solo in the clinic. I decided that I needed more knowledge so patients got the best care" $(P 1, Q 1)$.

The Irish leaders realized that developing as leaders did not occur without the help of others. These leaders described some of the strategies that helped them continue to develop and find a pathway to effective leadership.

"Learned to listen more. (I) tried to get a handle on what did management want and discovered that I needed to be part of the team" (P1, Q7).

"Need people to open doors and need people to support and not chop head off" (P4, Q4).

"Coaching received at a senior level was very beneficial; mentor and a coach in a leadership program really helped prepare and get through difficult situations" (P3, Final).

\section{Political Acumen}

The participants described the importance of political acumen as a strategy to implement change and progress the quality of patient care. Comments ranged from personal experiences of facing political barriers with little preparation to learning new improved strategies of managing the barriers within an already established political landscape.

"Still about who you know in Ireland; the connections are your inroad; important to do your homework first or it can end before it starts. Learn to listen better and convince others well" (P1, Q5).

"Learn about politics and how to get things done; recognize your values because they will be challenged and easy to trade out on them; learn conflict resolution skills" (P4, Q10).

"Good reputation needed for opportunities; personality style; need to have a combined hard and soft side; need straight speaking (direct) with political acumen; know how to make a pitch to the group without aggression or undermining individuals" (P4, Q5).

"Government role needs long term goals and influence of political perspective. Would have to really understand the Minister's view and influence of policies and plans" $^{\prime}(P 2, Q 7)$.

\section{Cultural Influence}

Aspects of the Irish culture are interwoven throughout participant data. Clearly, culture has a major influence on the nurse leaders' assertiveness when assuming the new role of leadership. One participant commented, "Culturally nurses are not very assertive in Ireland. Culturally nursing is "nice girls"; if bright want to do medicine. An important part of work is giving voice to marginalized group" (P4, Final Comments). Irish nurses were described as having a "special relationship with patients. Irish patients place a huge amount of belief and trust in 
the care they get from nurses. (We have a) social contract of the care that we deliver and public funded. Nurses are in service" (P2, Q5). Some believed that it was not within their comfort zone as a nurse to speak up or speak out about an issue. They were afraid of being seen as, "rude or disrespectful" (P1, Q6). These participants commented on Irish culture and its impact on nursing, as well as changes over time. One participant observed, "20 years ago silo culture in Ireland. (It) has changed. (Irish nurses have) adapted to more cultures and (other nurses) working abroad" (P3, Q4).

Participants commented on how cultural aspects impact perspective on the nurse as a leader and nursing as a profession. One participant stated, "Irish sense of humor not always understood outside the culture" (P3, Q5). Another participant stated, "Irish very quick as a nation to dismiss and criticize health system. (They) see the glass as half empty (and are) quick to complain" (P2, Q6). In order to be effective, "(you) need an insider and outsider ability to critic and make changes. (You need to) be a trouble maker in a way that you are invited back for a solution. (It is important to) demonstrate authenticity, honesty, and respect" (P4, Q6).

\section{Gender Norms}

Gender norms among the leadership roles for these nurses were easily realized as a theme in this study. Power struggles for females in this study, such as leadership role occupancy and power motivation proved to include a learning curve for them as much as it was about learning the process of becoming a leader of which they had no prior training. This study parallels the findings of Schuh et al. (2014), in which females were found to be underrepresented in leadership roles with little to no convergence of leadership occupancy or motivation (Schuh et al. 2014). For example, the evolving social structure of the Irish culture afforded little to no preparation for females to obtain leadership roles and many felt ill prepared even with some training for the role. The nurse leaders often reported a lack of orientation or any type of leadership training prior to moving into the role. Some participants described strategies for transitioning from a "female" nursing role to a "male" leadership role.

"All of the clinical nurse managers were religious women who were feminist and they pushed me for a degree; $1^{\text {st }}$ woman with first degree with hospital support and teaching qualifications; need people to open doors and need people to support and not chop head off" (P4, Q4).

"Nurse leaders taking on male attributes; more aggressive and more ego "I" values rather than participative values; politically engaged more aggressive; when not aggressive takes longer for value to be recognized" (P4, Final Comments).

\section{Discussion}

The historical influences on the development of nursing from religious order sisters and Florence Nightingale in the Republic of Ireland can be seen in the discussion and themes of cultural influences and gender differences. However, the 
advances in medical treatment and prevention provided opportunities for nurses to take on more independent practice roles within the healthcare system. Strong nurse leaders within the Republic of Ireland identified these opportunities and took action utilizing strategies such as participatory leadership style, assertive communication, and political acumen to influence the advancement of national policies, nursing education and advanced practice opportunities. Some examples of nurse leadership successes include being a founding member of national organizations, developing one of the first master in nursing programs, and creating safe nurse staffing and clinical protocols. These leaders opened doors for other nurses to have greater influence on enacting leadership roles. Nurse leaders worked to develop frameworks, such as the one developed by the National Council for the Professional Development of Nursing and Midwifery, to enact advance practice leadership roles (Higgins et al. 2014). Furthermore, the advanced practice nurses became members of local and national committees where they were able to shape healthcare reform and further develop nursing as a profession (Higgins et al. 2014). The impact of the leaders' actions was transformative in Ireland.

Even though these nurse leaders had a great impact on the progression of nursing within the Republic of Ireland, the female representation in Ireland in leadership roles appears to be lower than other countries. According to the Irish Management Institute (2018), female representation on boards of indexed companies in Ireland (13\%) lags far behind the other European countries with the United Kingdom at $28.4 \%$, Sweden at $36.1 \%$, and Italy at 33\% (Irish Management Institute 2018). In fact, women make up $16.3 \%$ of the Chief Executive Officers globally (Irish Management Institute 2018). One of the inhibitors for women moving into executive leadership position in the study was identified as women being less vocal (Higgins et al. 2014), which is one of the aspects of a lack of assertiveness in communication. Although the Irish Management Institute (2018) recognized that women generally have more of the qualities needed to be effective leaders, mentoring, coaching and sponsorship are strategies proposed to help women navigate through inhibitors found within the leadership development system (Irish Management Institute 2018). Some of the barriers for nurses moving into leadership roles within the United States and Europe may be related to some of these same gender norms. Utilizing political acumen within the cultural context to place nurses within national and international healthcare committees might be a viable strategy for other developed nations seeking to increase the influence of nursing as a profession.

\section{References}

Alvesson M, Sveningsson, S (2003) Managers doing leadership: the extra-ordinarization of the mundane. Human Relations 56(12): 1435-1459.

Commission on Nursing (1998) Report of the Commission on nursing: a blueprint for the future. Dublin, Ireland: Stationery Office, Government of Ireland.

Creswell J, Poth C (2018) Qualitative inquiry and research design: choosing among five traditions. $4^{\text {th }}$ Edition. Thousand Oaks, CA: Sage. 
Cruz EV, Higginbottom G (2013) The use of focused ethnography in nursing research. Nurse Researcher 20(4): 36-43.

Denzin N, Lincoln Y (2018) The sage handbook of qualitative research. $5^{\text {th }}$ Edition. Thousand Oaks, CA: Sage.

Fealy GM (2005) A place for the better technical education of nurses: the Dublin Metropolitan Technical School for nurses, 1893-1969. Nursing History Review 13(1): 23-47.

Higgins A, Begley C, Lalor J, Coyne I, Murphy K, Elliott N (2014) Factors influencing advanced practitioners' ability to enact leadership: a case study with Irish healthcare. Journal of Nursing Management 22(7): 894-905.

Irish Management Institute (2018) Women in leadership: inspire, influence, ignite. Retrieved from: https://bit.ly/3esv46q. [Accessed 13 December 2018].

Leydon I (1973) Development of nurse education in Ireland-training to meet the challenges of the future. International Journal of Nursing Studies 10(2): 95-101.

Morse J (2015) Critical analysis of strategies for determining rigor in qualitative inquiry. Qualitative Health Research 25(9): 1212-1222.

O'Dwyer P (2007) Looking back...moving forward: the educational preparation of nurses in Ireland. Nursing Education Perspectives 28(3): 136-139.

Schuh S, Bark A, Van Quaquebeke N, Hossiep R, Frieg P, Van Dick R (2014) Gender differences in leadership role occupancy: the mediating role of power motivation. Journal of Business Ethics 120(3): 363-379.

Scroope C (2007) Irish culture. Cultural Atlas. Retrieved from: https://culturalatlas.sbs. com.au/irish-culture/irish-culture-core-concepts. [Accessed 29 May 2018].

Teherani A, Martimianakis T, Stenforrs-Hays T (2015) Choosing a qualitative research approach. Journal of Graduate Medical Education 7(4): 669-670.

Van Manen M (1990) Researching lived experience: human science for an action sensitive pedagogy. Albany, NY: State University of New York Press. 
